\title{
RENOTE - crescimento em qualidade e quantidade
}

Apesar do difícil ano de 2020 tivemos um elevado número de submissões nesta edição da RENOTE. A RENOTE publica duas edições por ano, desde 2003 e em algumas ocasiões é publicado um número especial, dedicado a alguma temática específica.

A evolução da quantidade de submissões e de trabalhos aceitos, ilustrada no gráfico abaixo que mostra a quantidade de trabalhos submetidos e aceitos no último decênio, evidencia a importância desta publicação em termos de seu papel como veículo para divulgação dos trabalhos dos autores nacionais.

\section{RENOTE - Artigos submetidos e aceitos}

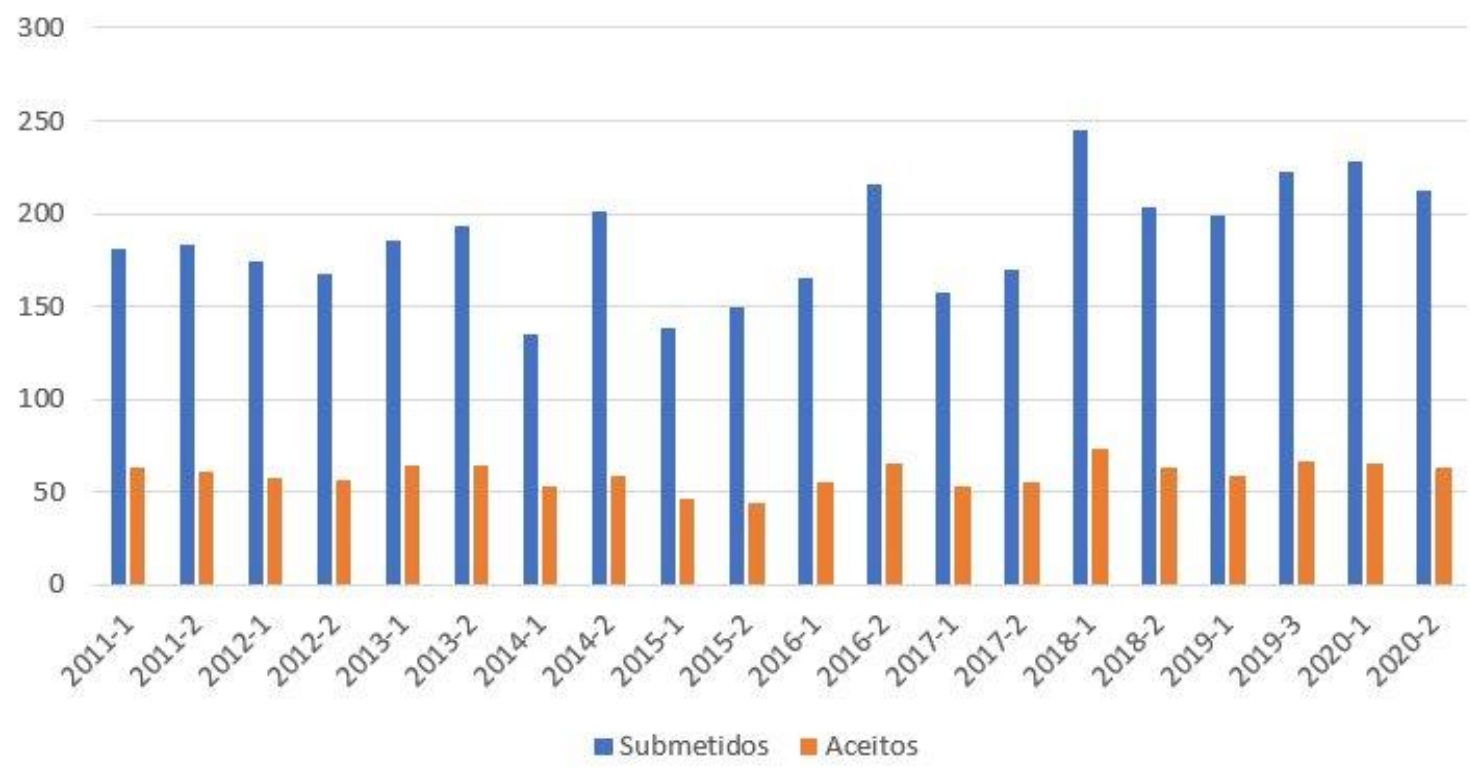

Nesta edição, foram recebidos 221 registros de artigos, sendo concretizada a submissão de 212 trabalhos, dos quais foram selecionados 63 , o que corresponde a pouco menos de $30 \%$, como é usual no processo de seleção da RENOTE. Dentre os trabalhos selecionados, 39 foram submetidos por autores de outros estados e países.

Trabalharam no processo de seleção 92 revisores provenientes de instituições de 5 outros estados do Brasil e de 2 outros países, $\mathrm{O}$ trabalho foi realizado na modalidade de revisão duplo cego dos artigos.

A temática abordada nos artigos publicados nesta edição mostra as novidades em temos de uso de novas tecnologias na educação, tais como ambientes virtuais de aprendizagem, tecnologias móveis, jogos educativos, laboratórios virtuais, aprendizagem colaborativas, mas também traz os subsídios teóricos que servem de apoio ao uso da tecnologia como recurso educacional.

A temática abordada pelos trabalhos pode ser delineada através do diagrama seguinte que mostra a nuvem das principais palavras chave utilizadas. 


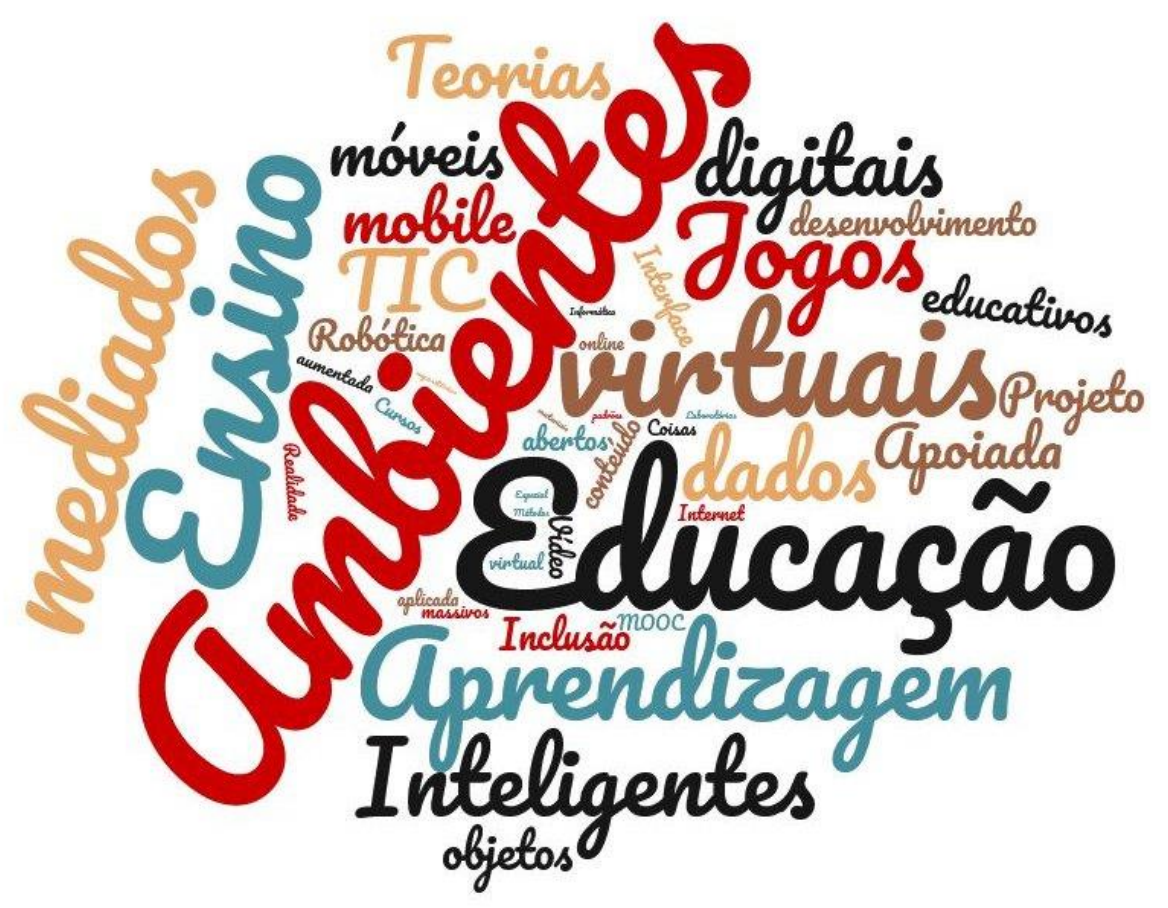

Os tópicos abordados com maior frequência nos artigos foram Ambientes virtuais de aprendizagem bem como Ensino e aprendizagem mediados por computador. $O$ gráfico seguinte ilustra a frequência de trabalhos em que cada um dos tópicos foi selecionado.

Tópicos selecionados

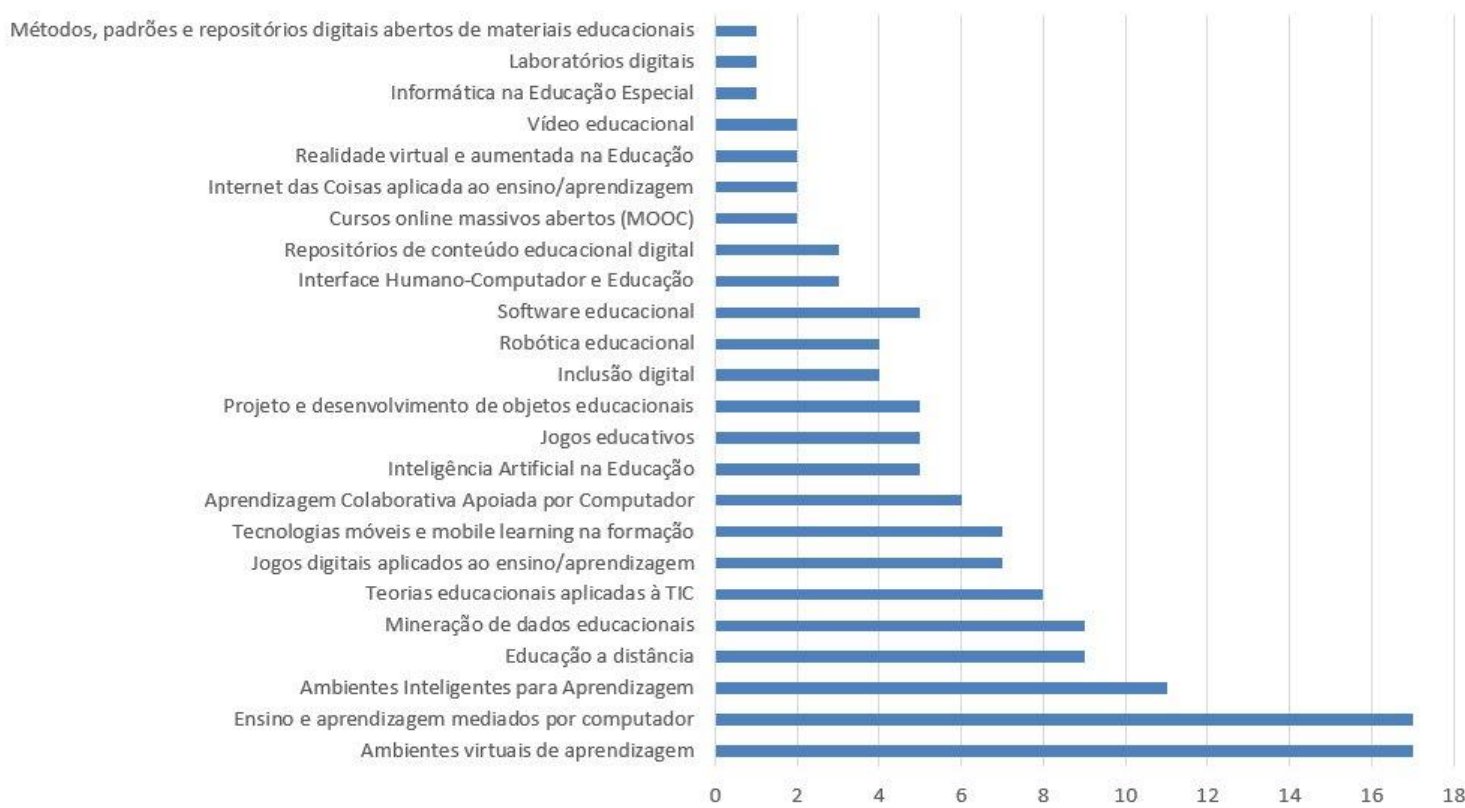

A indexação da RENOTE no Google acadêmico, mostra que a revista tem sido fonte de referência significativa com um índice h5 de 10 (a partir das métricas do próprio Google Scholar) o que a coloca no nível das revistas do estrato superior da classificação Qualis da CAPES. Atualmente a RENOTE está classificada como A4 no novo Qualis (ainda não oficial). 
O h-index geral da RENOTE, calculado pelo programa Publish or Perish a partir de pesquisa no Google scholar é atualmente 39 e que corrobora o alto impacto da revista na comunidade mostrando que ela é referência de destaque para os autores no país e mesmo fora.

Também cabe destacar que a RENOTE está indexada no Portal de Periódicos da CAPES, no LATINDEX, no PKP - Public Kowledge Project, no portal LivRe - Revistas de Livre Acesso, IBICT, além do Google Scholar.

Liane Margarida Rockenbach Tarouco

Editora

RENOTE - Revista Novas Tecnologias na Educação 